\title{
Nietzsche, ¿un pensador alejado de la política y de lo político?
}

\author{
Jorge Polo Blanco \\ Escuela Superior Politécnica del Litoral (Ecuador) \\ polo@espol.edu.ec
}

Fecha de recepción: 19-10-2020

Fecha de aceptación: 14-5-2021

\section{Resumen}

En el presente trabajo intentaremos mostrar que la filosofía de Nietzsche, contrariamente a lo que se ha sostenido en demasiadas ocasiones, es también una filosofía política. Ese pensar político evidenció, por lo demás, un sesgo eminentemente reaccionario y elitista. Cualquier discurso político de signo igualitarista producía en los oídos de Nietzsche una lacerante molestia. Nos hallamos ante un pensador tremendo y profundo que reaccionó con sumo horror ante los hechos de la Comuna de París, aplaudiendo su sangriento aplastamiento. Comprobaremos, por ende, que siempre estuvo al tanto de la coyuntura sociopolítica de su época. Sintió en todo momento un odio visceral —una aversión irreprimible- por la democracia, por los ideales ilustrados, por el movimiento obrero y por el socialismo.

Palabras clave: Nietzsche; filosofía política; cuestión social; aristocratismo; elitismo; antisocialismo

Abstract. Nietzsche, a thinker unconcerned with politics and the political?

In this paper we will attempt to show that Nietzsche's philosophy, contrary to what has too widely been believed, is also a political philosophy. Moreover, this political thinking demonstrated an eminently reactionary and elitist bias. Any political discourse of an egalitarian nature was offensive to Nietzsche. We are dealing with a formidable and profound thinker who reacted with great horror to the events of the Paris Commune, applauding when it was ruthlessly suppressed. We will thereby demonstrate that he kept abreast of the socio-political developments of his time. He felt at all times a visceral hatred - an irrepressible aversion - for democracy, for Enlightenment ideals, for the labour movement and for socialism.

Keywords: Nietzsche; political philosophy; social issue; aristocratism; elitism; anti-socialism

\section{Sumario}

\section{Contra las lecturas despolitizadoras}

2. La biografía de un reaccionario radical

3. La Comuna de París

4. La Hidra Internacional
5. La dionisiaca guerra

6. No se puede extirpar lo inextirpable

7. A modo de conclusión

Referencias bibliográficas 


\section{Contra las lecturas despolitizadoras}

Las hermenéuticas del pensamiento nietzscheano siempre derivaron por cauces tumultuosos y agitados. Después de la Segunda Guerra Mundial se produjo la «rehabilitación» de una filosofía que había sido adulterada, tergiversada y groseramente manipulada. Desnazificarlo era tarea perentoria. Múltiples elementos ideológicos se habían adherido espuriamente a un pensamiento que debía ser, en cierto modo, «recuperado». Y, para ello, se adoptó una estrategia expedita pero sustancialmente equivocada: la mejor fórmula para desvincular a Nietzsche del fascismo consistía, sencillamente, en despolitizarlo. Si se construía la imagen de un filósofo meramente esteta u ontológico, ajeno e incluso hostil al universo político, todos los funestos malentendidos quedarían inmediatamente deshechos. El péndulo de la hermenéutica nietzscheana, de tal modo, se había movido hacia el otro extremo; desde una politización ilegítima y parcialmente desvirtuada se pasó, ulteriormente, a una neutralización política de su pensamiento (Ansell-Pearson, 1994). Sin embargo, y es lo que pretendemos mostrar en este pequeño trabajo, esa neutralización es tan errada como su politización nacionalsocialista.

La inclusión de Nietzsche en el grupo de "pensadores apolíticos» sigue siendo muy habitual, aunque tal ubicación resulte insostenible (Polo Blanco, 2020). Ciertamente, la dimensión política del pensamiento nietzscheano ha sido lúcidamente revisada en algunas ocasiones (Siemens y Roodt, 2008). Y es que, desde un punto de vista puramente cuantitativo, la materia textual que de forma más o menos explícita se refiere a temas políticos es abundante. Son muy numerosos los pasajes donde aborda esos asuntos, ya sea en textos publicados o en textos póstumos. Que dichos pasajes se hallen diseminados, o imbricados con otras temáticas, no quiere decir que no sean medulares y constitutivos; entre otras cosas, porque en Nietzsche todo se halla diseminado e imbricado. Pero, además, y esto es lo más decisivo, ese pensar político guarda íntima afinidad con los núcleos más importantes y ardorosos de su filosofía. No se trata, por lo tanto, de una cuestión marginal o anecdótica. Bien es verdad que su forma de escribir no ofrece facilidades, y que su pensamiento político se halla disperso y enmarañado de mil maneras, aunque a veces es muy crudo y explícito. Su lenguaje polisémico y metafórico, cargado de vituperante y profética grandilocuencia, tampoco invita a la serenidad analítica. Pero, en medio de sus ardientes fogonazos, podemos descubrir ciertas coherencias internas que, a la postre, configuran un pensamiento político. Creemos, en ese sentido, que Heidegger (2013: 17-34) tenía toda la razón cuando remarcaba que, en el universo teórico nietzscheano, la «voluntad de poder» ocupaba una posición medular. Sin embargo, no quiso extraer las conclusiones políticas que, a nuestro modo de ver, se derivaban de semejante ontología. Localizó correctamente el nudo primordial del pensamiento nietzscheano, pero, al mismo tiempo, lo despolitizó. Y, en esto último, ya no podríamos coincidir con el que fuera rector de la Universidad de Friburgo.

Nietzsche siempre tuvo muy claro quiénes eran sus enemigos. Es cierto que su labor primordialmente disolvente no lo condujo a la terminación de 
un programa político concreto. Sin embargo, es indudable que su obra sí alberga un nítido contraprograma: sabía muy bien quiénes eran sus contrincantes políticos, pues sobre ellos arrojaba la metralla dialéctica más corrosiva, y tenía muy claro qué órdenes sociopolíticos eran los menos deseables. Se mostró extremadamente conmocionado por la expansión de lo que él mismo denominó la Hidra Internacional, y no es este un dato menor. Su moral aristocrática no encerraba ninguna metáfora empleada para el trazo de una crítica «cultural» y «estética» de la civilización occidental; esa visión aristocrática del mundo, por el contrario, era absolutamente literal y visceral. Experimentaba sincera repugnancia por todo lo plebeyo, por las obtusas clases populares. Y, más allá de su labor crítico-disolutiva, también podemos localizar en su obra ciertas propuestas normativas. Propuestas harto inquietantes, desde luego.

Se ha pretendido «recuperar» a Nietzsche para una cultura y una sociedad democráticas (Salem Himmich, 2002). Pero el filósofo de la «voluntad de poder» no sentía demasiadas simpatías por el empoderamiento popular. Tal afirmación, de hecho, se quedaría demasiado corta, porque Nietzsche experimentaba una hondísima repugnancia por todos los movimientos filosóficopolíticos que, en su propio tiempo, propugnaban semejante empoderamiento de las clases trabajadoras, o de los «sectores populares», diríamos hoy. Nos interesa comprobar, por ejemplo, que siempre rechazó con amargura la implantación del sufragio universal, por suponer este el triunfo de los más débiles, un sistema en virtud del cual las naturalezas más bajas se imponen a las superiores y más contrastadas. Semejante conquista democrática representaba a sus ojos el triunfo de la mediocridad, una sucia hegemonía de los hombres inferiores. Es palpable su incapacidad manifiesta a la hora de comprender y valorar el mecanismo democrático; no podía admitir que la «mayoría» tuviese la legitimidad de determinar el rumbo colectivo, precisamente a través del sufragio universal (Nietzsche, 1988: 142-143). La "supersticiosa» creencia en la igualdad, encarnada en todos los representantes de la decadencia y el resentimiento (demócratas radicales, jacobinos, socialistas o anarquistas), desembocaba irremisiblemente en un marasmo de mediocridad en el que terminaban sucumbiendo las naturalezas superiores. "Ya todo se ha convertido en plebe», una quejumbrosa frase en la que pudiéramos detectar una peculiar mezcla de rabia, desasosiego y melancolía.

Su «visión trágica del mundo» se traducirá en un orden social marcadamente elitista; un orden que aparecerá como antagónico de todas las instituciones políticas propias de la "civilización socrática»: democracia, sufragio universal, igualdad ante la ley o derechos del trabajador. Todos estos elementos, que de forma genérica podríamos identificar con el programa político-cultural de la Ilustración, fueron detestados por Nietzsche hasta el fin de sus días (Esteban Enguita, 2004: 61-71). También se opuso frontalmente a la generalización de la instrucción pública (Nietzsche, 2009). El «pathos de la distancia», que separa a los poderosos de los inferiores, no debiera ser extirpado. Lo piadoso, lo filantrópico, lo altruista, lo desinteresado, lo fraterno y lo compasivo son 
ideales deletéreos y ponzoñosos, pues todos ellos socavan y arruinan las fuentes de la vida. Esa compasión democratizadora, en suma, es un movimiento que atenta directamente contra el impulso fundamental de lo viviente. He aquí una tesis tremenda, pero nuclear para comprender su pensamiento. Repitámosla, para retener todas sus implicaciones: el avance del «espíritu democratizador", genealógicamente vinculado a la compasión cristiana, es un movimiento que atenta directamente contra una cosa denominada «impulso fundamental de lo viviente».

Lo que se deriva de semejantes premisas es algo demoledor. Nietzsche está insinuando que el derecho debe permanecer, en todo caso, naturalizado; porque es el devenir agonístico de la vida el que da —o debería dar — la medida de lo justo y lo injusto. Ninguna norma que sea extrínseca al devenir de lo viviente puede osar establecer un criterio de lo bueno y lo malo. Será justo, desde la perspectiva de la vida, todo aquello que permita o promueva que lo naturalmente superior prevalezca; será justo aquello que impulse un movimiento constante de lo vigoroso, aquello que les permita a los fuertes, a los «bien constituidos», conservar su rango y acrecentar su preeminencia. Será justo - en esta perspectiva nietzscheana- aquello que no pretenda interrumpir o corregir la ordenación natural y vital del mundo.

\section{La biografía de un reaccionario radical}

El 3 de enero de 1889 algo verdaderamente insólito sucedió en la piazza Carlo Alberto, Turín. Tras un repentino alboroto producido por un cochero que castigaba a su caballo, un extraño personaje corrió hacia el animal para abrazarse con fuerza a su cuello, queriéndolo proteger de la reprimenda; después, al parecer, se desvaneció. Tal escena, pintoresca y llamativa, fue protagonizada por un alemán. Días después, el personaje en cuestión escribía breves cartas a algunos de sus amigos, y en ellas mostraba evidentes signos de megalomanía y una demencia creciente. Lo llevarían a una clínica psiquiátrica en Basilea, precisamente la misma ciudad en la que años atrás había obtenido su cátedra universitaria de Filología. Pero no sería la última clínica que visitaría. Nunca se recuperó y, bajo los cuidados de su hermana Elisabeth, vivió sus últimos años en Weimar, donde falleció el 25 de agosto de 1900. Fue enterrado en Röcken, el pueblecito donde había nacido. Un final desgraciado y sufriente para una de las figuras más determinantes e influyentes de la cultura occidental contemporánea. Porque a Friedrich Wilhelm Nietzsche no cabe ignorarlo. Habermas, en ese sentido, emitió un juicio muy apresurado en 1968; un juicio completamente erróneo, en realidad: «Nietzsche ha perdido por completo su capacidad de contagio" (1982: 31). Muy al contrario, su influencia pervive en múltiples espacios de la cultura occidental, desbordando los límites de la filosofía académica. Y lo cierto es que un gigante del pensamiento no puede ser saltado, ni rodeado. No hay escapatoria posible, se torna perentorio entrar en él y dejarnos atravesar por él. Eso sí, son múltiples las maneras de abordarlo; existen interpretaciones muy diferentes e incluso antagónicas. En 
las páginas que siguen ensayaremos una lectura que ya tantearon otros pensadores, pero intentaremos darle un énfasis más vehemente.

Y seremos heterodoxos desde el comienzo, toda vez que afirmaremos que los análisis de Georg Lukács en Die Zerstörung der Vernunft, obra aparecida en 1954, siguen siendo cruciales para situar e interpretar la filosofía nietzscheana en su justa medida, y ello a pesar de que sobre dicha interpretación se superponen densísimos «lustros posestructuralistas» que vinieron a ofrecer una lectura muy distinta de la obra de Nietzsche. En muchas ocasiones se ha podido acusar a Lukács de caricaturizar el pensamiento nietzscheano, como si el filósofo nacido en Budapest hubiera construido una suerte de anacrónico «Nietzsche hitleriano». Pero también se ha hecho una caricatura de «lo que Lukács dijo sobre Nietzsche», pues en verdad los análisis del marxista húngaro son refinados y penetrantes.

Lo coherente y lo sistemático radica precisamente en el contenido social de su pensamiento: en la lucha contra el socialismo. Si consideramos desde este punto de vista los abigarrados y multiformes mitos nietzscheanos, contradictorios entre sí, descubrimos en seguida su unidad final, su intrínseca concatenación: todos ellos son mitos de la burguesía imperialista encaminados a movilizar todas las fuerzas contra su enemigo fundamental. No resulta difícil descifrar que la lucha entre los señores y la horda, entre los hombres superiores y los esclavos, es simplemente la contrafigura míticamente caricaturesca de la lucha de clases. (Lukács, 1968: 322)

Tal radiografía siempre incomodó sobremanera a ese «oficialismo nietzscheano» que se configuró desde los años setenta en adelante, ese cuerpo de interpretación que fue tornándose canónico y hegemónico.

Pretendemos ahondar, en lo que sigue, en esa controversia ya abierta por Lukács. Y, posicionándonos muy nítidamente desde el comienzo, sostendremos que la obra de Nietzsche se fue desarrollando en una constante polémica contra el socialismo (o contra la "democracia», más genéricamente). Es más, ignorar tal premisa conllevaría un desenfoque importante a la hora comprenderla, y ello a pesar de que «en materia de economía la ignorancia de Nietzsche es tan supina como la del intelectual medio de su tiempo» (Lukács, 1968: 256). Pero esto no implica en modo alguno que dejara de olfatear un peligro que, a sus ojos, era tremendo. "Los filósofos saben instintivamente lo que tienen que defender y dónde está el enemigo. Se percatan instintivamente de las tendencias "peligrosas" de su tiempo, e intentan darles la batalla en el terreno de la filosofía» (Lukács, 1968: 253). Una serie de acontecimientos y procesos históricos causaron honda impresión en su espíritu, y entre ellos no ocuparon un lugar menor la Comuna de París de 1871, el desarrollo (especialmente fuerte en Alemania) de las organizaciones obreras de masas o las leyes de excepción dictadas por Bismarck contra los socialistas, en 1878. Ese es el marco sociopolítico en el que piensa y escribe Nietzsche, y no puede soslayarse de ningún modo, salvo que queramos elaborar sobre su obra una hermenéutica radicalmente descontextualizada. Esta premisa de Lukács nos sigue pareciendo esencialmente correcta, y en ella abundaremos. 
Es por lo anterior que afirmaciones como las de Karl Löwith, cuando señala que Nietzsche "prestó poca atención a las cuestiones sociales y económicas» (1968: 247), no parecen del todo justificadas. Quizás nunca se ocupó de Marx, y no escribió folletos u opúsculos explícitamente económico-políticos, pero, como agudísimo auscultador de su mundo, Nietzsche enjuiciaba constantemente el espíritu que latía en la médula de los grandes movimientos filosófico-políticos de su tiempo. Como diagnosticador crítico de la cultura europea, fijaba su atención en los desplazamientos telúricos y tectónicos, por así decir, que se estaban produciendo ante sus ojos. Dichos desplazamientos, empero, tenían manifestaciones sociopolíticas concretas, coyunturales y epocales, a las que siempre prestó muchísima atención. Nos parece absolutamente errada, en este sentido, la siguiente afirmación de Eugen Fink: «Hay que rechazar con toda decisión los intentos de introducir a Nietzsche en la política del momento» (1976: 11). Y, un poco más adelante, añade que la interpretación de su obra se «resiente» cuando «se emplea la biografía como clave» (p. 13). Nuestra propuesta, sin embargo, vulnera esas prohibiciones, porque sostenemos que su pensamiento se fue construyendo, indiscutiblemente, en medio de la convulsión social y espiritual que sacudía el continente, y ello a pesar de sus episodios biográficos de eremita montaraz.

\section{La Comuna de París}

El acontecimiento revolucionario más atronador, esplendoroso y traumático de todo el siglo XIX sucedió en París, como ya hemos señalado. Pero ahora debemos ubicarnos en el momento posterior, esto es, cuando el experimento social ha sido aniquilado y los comuneros son machacados de forma inmisericorde. Uno de los países más solidarios y humanitarios con los refugiados de la Comuna derrotada, que huían de la feroz represión desatada en toda Europa, fue Suiza. Allí se encontraba en esos precisos momentos Nietzsche, que contemplaba horrorizado esa acogida ofrecida por el país helvético. Los communards asilados editaban folletos, periódicos y libros; delegados de la Internacional llegaban desde todos los puntos del continente europeo, y celebraron sus congresos en Ginebra, Lausana y Basilea, ciudad esta última donde Nietzsche obtuvo su cátedra en Filología. Y todo ello, no cabe la menor duda, conmocionaba al pensador dionisiaco. "iNietzsche estaba absorto e indiferente a los sucesos histórico-políticos, como sostiene la escuela de interpretación tradicional, la hermenéutica de la inocencia del Nietzschéisme?»" (González Varela, 2010: 94). Resultaría insostenible responder afirmativamente a semejante cuestión, toda vez que mantenía asidua correspondencia con el reaccionario Carl Ernst von Gersdorff, un oficial en activo del ejército prusiano que, durante los episodios de la Comuna, permaneció acampado en Saint Denis, a solo nueve kilómetros del centro de la ciudad, participando en el sitio de la misma. Desde allí, a tan corta distancia del núcleo ardiente del mayor conflicto social que jamás hubiera azotado a la Europa moderna, escribía al filósofo alemán, el cual seguía los acontecimientos con vivo interés. 
Gersdorff, en los primeros días de abril de 1871, justo una semana antes de la proclamación de la Comuna, le espetaba a su amigo Friedrich con tono de extremada preocupación, y con evidente complicidad, que dónde estaban los hombres de acción capaces de ponerle un freno perdurable al «movimiento de los rojos» (González Varela, 2010: 94). E inmediatamente después de que los comuneros fueran sanguinariamente aplastados, Nietzsche escribe estas palabras a su amigo:

Si hay algo que puede subsistir para nosotros tras este bárbaro período de guerra, es el espíritu heroico y al mismo tiempo reflexivo de nuestro ejército alemán, espíritu que, para mi sorpresa, como descubrimiento casi bello e inesperado, he encontrado fresco y vigoroso, con el antiguo vigor germánico. Sobre esta base se puede construir. ¡Nuestra misión alemana aún no ha acabado! [...] Todavía hay valentía, y valentía alemana. Más allá del conflicto de las naciones, nos ha dejado aterrorizados, por lo terrible e imprevista, la sublevación de la Hidra Internacional, presagio de muchas otras luchas futuras. (González Varela, 2010: 95)

Nietzsche sentía verdadero pavor ante la potenciación de las luchas obreras organizadas, y su alivio fue inmenso cuando estas fueron arrolladas después de haber ensayado un orden social nuevo que lo ponía todo del revés. El ejército prusiano (la "misión alemana», decía) contribuyó de forma portentosa a dicho aplastamiento, porque nuestro filósofo tenía un enemigo muy claro, a saber, esa internationale Hydrakopf que asomó sus garras para sacudir los cimientos sociales de Europa. Nietzsche no duda en emplear ese término, Hidra, esgrimido y azuzado por toda la prensa reaccionaria más o menos sensacionalista, para referirse a la AIT (organización en la que estaban Marx y Bakunin, como es bien sabido, y que ulteriormente sería conocida como Primera Internacional). Tenemos aquí, por lo tanto, unos elementos biográficos que van dibujando y perfilando la estructura intelectual del filósofo. $Y$ es verdaderamente improcedente pretender que tales hechos, bien documentados, no son significativos a la hora de comprender su pensamiento.

Nietzsche identifica a los socialistas como los «nuevos bárbaros», esas hordas pestilentes que destruirán la alta cultura europea. Recordemos que Zaratustra advertía que el manantial de la vida quedaba emponzoñado cuando la "chusma» bebía en él (Nietzsche, 1998: 155). Un "pueblo» jamás podrá imaginarse como algo noble y elevado; la chusma ovejuna, resentida y pedigüeña es incapaz de crear, por sí misma y desde sí misma, algo grandioso. Para Nietzsche, feroz elitista, no existe «cultura popular» digna de tal nombre; es más, semejante noción constituiría para él una suerte de oxímoron. Y podemos observar, en perfecta consonancia con tal actitud, que el desprecio que muestra por la revolución social es, en todo momento, infinito. Quedó existencialmente golpeado cuando dio pábulo al falso rumor, inventado y pregonado por la prensa reaccionaria, sobre el incendio del Museo del Louvre perpetrado por los comuneros. Al parecer Nietzsche lloró de rabia e impotencia ante semejante «suceso» (González Varela, 2010: 96). Y, aunque este factor apenas haya sido señalado o 
comentado, el inicio de su ruptura con Richard Wagner tuvo algo que ver con la experiencia de la Comuna, pues ante estos acontecimientos el músico se encontraba bastante más «a la izquierda» que Nietzsche (Wagner incluso había sido compañero de Bakunin en la revolución de 1848). No solo hubo «motivaciones estéticas» en aquella celebérrima ruptura. Y, en cualquier caso, el «estremecimiento artístico» del filósofo (tan intensamente evidenciado por la falsa noticia del incendio del Louvre) no se hizo eco de la carnicería desatada. El espectáculo sanguinolento y criminal no incidió en su nervio espiritual (González Varela, 2010: 97). Ejecuciones masivas y sumarias, más de treinta mil personas ajusticiadas (incluidos niños y niñas) una orgiástica represión en la que se emplearon por primera vez ametralladoras. Deportaciones, persecuciones, encarcelamientos. Mientras Wagner consignaba en sus diarios, con impresión horrorizada, la magnitud y la extremada dureza de esa reacción, Nietzsche guardaba sobre todo ello un granítico y siniestro silencio. De hecho, volvemos a remarcarlo, solo tomó la pluma para celebrar sin ambigüedades y con regocijo la derrota de la Comuna (Montinari, 2003: 71-73).

\section{La Hidra Internacional}

Pero hay más episodios, que algunos tal vez considerarán anécdotas irrelevantes y que en realidad son la fragua misma de su visión del mundo. Ya antes del estallido de la Comuna, Nietzsche había sido testigo directo de otro acontecimiento histórico de gran relevancia: el cuarto congreso de la Asociación Internacional del Trabajo, celebrado en Basilea en septiembre de 1869. La batalla contra el patriciado oligárquico de esta ciudad (un encarnizado conflicto social, jalonado por virulentas huelgas, que Nietzsche vivió en primerísima persona, entre otras cosas por los vínculos sociales que mantenía con las clases altas de la ciudad) había colocado a esta sección de la Internacional en la vanguardia del movimiento obrero europeo, por lo que era natural que se eligiese a Basilea como sede honorífica para el cuarto congreso. Este fue anunciado en la prensa suiza como un verdadero acontecimiento. Se inauguró el encuentro el 5 de septiembre con una manifestación enorme que recorrió las principales calles de la ciudad, y la llegada de los ochenta delegados internacionales fue recibida y vitoreada por una multitud de obreros. Se realizó un acto solemne en el punto neurálgico de la ciudad, la Aeschenplatz, situada en el corazón del centro histórico. Fue un mitin fervoroso repleto de discursos y música festiva. El congreso, cuyo lema principal era el ya mítico "proletarios del mundo, uníos", deliberó durante toda una semana, con sesiones públicas y a puertas abiertas, en el Café National, un establecimiento que se hallaba a unas pocas decenas de metros de la entrada principal de la Universidad de Basilea y del portal por el cual ingresaba todo el cuerpo profesoral, incluido el joven profesor de Filología, un tal Friedrich Nietzsche. Colegas suyos en la Universidad, como el economista Von Schönberg, intervinieron en el debate para analizar algunas dimensiones de la "cuestión obrera». Es de todo punto inconcebible, por lo tanto, que Nietzsche no prestara atención a un evento de semejante magnitud; 
muy al contrario, parece evidente que las sucesivas oleadas obreras y socialistas despertaron en él una tremenda inquietud, dejando indeleble huella en gran parte de sus escritos, lo mismo en los publicados que en los no publicados. La agitación obrera, incluso, le golpeó directamente cuando las huelgas de tipógrafos en Leipzig afectaron a su editor, Fritzsch, el cual, por cierto, era también el editor de Richard Wagner. Ante semejantes conmociones mantenía una perspectiva de clase muy definida. En Basilea, de hecho, solo se relacionaba con familias patricias conservadoras, que observaban con espanto y horror las sublevaciones obreras. Bien podemos imaginar que, sumido en esa atmósfera existencial, sus sentimientos hacia los huelguistas no eran demasiado empáticos (Janz, 1987: 221).

Ya antes del congreso de la AIT Nietzsche había sido testigo, como decíamos hace un momento, de un conflicto social de primera envergadura. Y, desde luego, su postura no fue la de un esteta apolítico.

En este contexto quizá no sea superfluo resaltar que Nietzsche anuncia su concepción trágica del mundo también en la política cotidiana. Se pronuncia contra la disminución de la jornada laboral; en Basilea se trataba de pasar de doce a once horas al día. Defiende además el trabajo de los niños; en Basilea a partir de los doce años de edad se permitían jornadas de diez a once horas diarias. Y se pronuncia igualmente contra las asociaciones para la formación de trabajadores. Opina de todos modos que las crueldades no han de llevarse demasiado lejos. La vida del trabajador ha de ser soportable, «a fin de que él y su descendencia trabajen bien en favor de nuestra descendencia». (Safranski, 2001: 158)

Esa última frase, citada por Safranski, la dijo Nietzsche en El caminante y su sombra (1988). Estaba en contra de reducir la jornada laboral de doce a once horas, estaba en contra de prohibir el trabajo infantil, estaba en contra de las escuelas obreras y de las asociaciones gremiales o sindicales. Semejante posicionamiento político, empero, no fue un devaneo de juventud o un episodio anecdótico; muy al contrario, responde a una concepción del mundo que permanecerá inalterada el resto de su vida. Esa toma de posición ante la «cuestión social», absolutamente elitista y clasista, tenía mucho que ver con los hilos profundos que tejían su pensamiento filosófico.

Es muy sintomático que en su obra sobre Nietzsche de 1965, Gilles Deleuze (2000) no mencionara, ni de pasada, tales acontecimientos biográficos, quizás porque no tuviera un conocimiento nítido sobre ellos o tal vez porque el francés consideraba que eran anécdotas menores e insignificantes. Tampoco Gianni Vattimo, cuando habla de la primera filosofía de Nietzsche en el período de su enseñanza en Basilea, menciona sus consideraciones sobre la Comuna, el socialismo o el movimiento obrero; simplemente refiere sus «veneraciones juveniles» hacia Wagner o Schopenhauer (Vattimo, 2001: 21). Pero de sus aversiones juveniles, que lo acompañarán invariable y determinantemente a lo largo de toda su madurez, y que fundamentalmente tenían que ver con su odio profundo hacia las fuerzas políticas igualitaristas y populares que emergían con 
muchísima fuerza y ardor en el corazón de Europa, no hay ni rastro en la obra del pensador italiano. Pero, ¿̨ómo iba Nietzsche a soslayar la «cuestión obrera», cuando la tenía literalmente delante de sí? La soziale Frage ocupaba una posición nuclear en su interpretación desasosegada de la vida moderna, aunque no mencionase jamás a Marx o a Engels (sí hizo, en cambio, referencias a Bakunin y a Lassalle). Sin embargo, se sabe que en su biblioteca había material bibliográfico sobre algunos estudios económicos. En algunos de esos volúmenes se hacía referencia a las teorías de Engels y Marx, e incluso en varios de aquellos textos el nombre de este último aparece subrayado con doble línea (Brobjer, 2008: 70).

Los Wagner, incluso, aconsejaron a Nietzsche no incluir en su primera gran obra ciertos elementos sociopolíticos, por ser excesivamente reaccionarios (González Varela, 2010: 109). Porque, y he aquí un elemento importante, una temática tan aparentemente alejada de la «moderna cuestión social» —el origen de la tragedia griega - se hallaba atravesada, sin embargo, por las cuestiones políticas y las derivas sociales más acuciantes de su inmediata contemporaneidad. Su crítica frontal al «socratismo», por ejemplo, se encuentra tamizada por la irrupción protagónica, portentosa y violenta de las clases populares europeas. $\mathrm{Y}$ es por dicho motivo que presta mucha atención a la oclocracia, que era el nombre despectivo utilizado por la aristocracia antigua para referirse al predominio, en la polis, del voto mayoritario de la muchedumbre y el vulgo. En vista de ello podemos sostener que Nietzsche despreciaba los procesos «democratizadores» en la Atenas clásica porque también los despreciaba en la Europa del siglo XIX. Su interpretación del antiguo mundo helénico, en suma, venía en cierto modo determinada por su visión política del mundo contemporáneo. No podemos olvidar que el tópico elegido por el jovencísimo Nietzsche para su disertación en Schulpforta fue Teognis de Megara, el poeta griego del siglo vi aC partidario del código de valores individualista y aristocrático. En ese análisis de su vida, su producción lírica y su visión ético-política, podemos observar la profunda simpatía nietzscheana por aquella cultura aristocrática que se vio profundamente amenazada por la irrupción victoriosa de las capas populares (Cristi y Velásquez, 2018). Aquellos procesos incipientemente democratizadores arruinaron la cosmovisión aristocrática que Teognis encarnaba. Pero debemos comprender, insistamos en ello, que las meditaciones de Nietzsche sobre la antigua Hélade - lo mismo en este trabajo juvenil que en la ulterior El nacimiento de la tragedia - se hallaban íntimamente vinculadas a sus posicionamientos ético-políticos en el tiempo presente.

\section{La dionisiaca guerra}

Otro episodio histórico prefigurará el espíritu de Nietzsche, también en su juventud. En el verano de 1870, mientras redacta los primeros compases de su visión dionisíaca del mundo, estalla la guerra franco-prusiana (o, más extensivamente, franco-germana). Semejante acontecimiento será contemplado por nuestro filósofo como una irrupción del «espíritu trágico» largamente sepul- 
tado por capas de molicie civilizatoria. Una voluntad terrible y elemental (la más elemental de todas) brotó desde los abismos profundos del ser; se trataba de una corriente telúrica demasiado tiempo silenciada. Lo dionisíaco, comprendido como una superación del principio de individuación, aparecía como una suerte de disolución extática en el mundo primigenio de la naturaleza; una quiebra de los principios ordenadores de la cultura que, de algún modo, nos retrotraía a una embriaguez horrendamente prelógica. La guerra era un momento de excepcionalidad radical, una fractura en la parsimonia civilizatoria, una grieta a través de la cual podíamos contactar con los abismos de ese mundo primigenio. El magma dionisiaco (como fondo último de la vida) era en realidad aquel devenir heraclitiano en el cual la guerra figuraba como principio dinámico de todas las cosas. En Humano, demasiado humano, obra publicada en 1878, encontraremos esa misma visión; en el parágrafo 477 señala que la guerra es «indispensable». Pero no se trata únicamente del reconocimiento de una suerte de fatalidad, algo así como una constatación de que las guerras siempre existirán, por mucho que bramen contra ellas los utópicos pacifistas. Lo anterior conllevaría una comprensión de que la guerra es una "fatalidad», esto es, algo que ineluctablemente ocurrirá, nos guste o no nos guste. Pero no es solamente eso; Nietzsche indica que las guerras son, además, indispensables; en ellas, o gracias a ellas, se vigoriza y se viriliza la cultura. Una guerra puede servir de phármakon o remedio curativo - estimulante energético - para pueblos demasiado agotados. Es deseable que estallen terribles conflagraciones, porque

[...] no conocemos otro medio que pueda devolver a los pueblos fatigados esa ruda energía de los campos de batalla, ese profundo odio impersonal, esa sangre fría en el homicidio unida a una buena conciencia, ese común ardor organizador en el aniquilamiento del enemigo, esa orgullosa indiferencia ante las grandes pérdidas, por su propia vida y por la de las personas amadas, ese quebrantamiento sordo de las almas comparable a los temblores de tierra, con tanta fuerza y seguridad, que no le preocupa cualquier gran guerra: los arroyos y los torrentes que se abren camino entonces, arrastrando, es cierto, en sus cauces piedras y fangos de toda especie y arruinando los prados de cultivos un poco delicados, vuelven a poner en seguida en movimiento, en circunstancias favorables, las ruedas de los telares del espíritu, que vuelven a moverse con nuevo ímpetu. (Nietzsche, 2001: 268)

La guerra cataliza el rejuvenecimiento espiritual de los pueblos, pues resurgen con ella las energías más profundas de aquel subsuelo primigenio.

En el verano de 1870, un joven Friedrich de 26 años se alista en el servicio de sanidad del frente, aunque Cosima Wagner trate de disuadirlo. Bien es verdad que ella misma, en un ardiente arrebato, escribió a Nietzsche quejándose amargamente de la pérfida arrogancia francesa y proclamando la inevitabilidad de una guerra que debía ser llevada a término hasta completar la «aniquilación» de la vanidad parisina; así, además, quizás se inaugurase la unidad alemana (Janz, 1987: 85). Sea como fuere, emprende su camino hacia el rugido armado y será testigo de escenas dantescas, recogiendo cadáveres en el 
campo de batalla, transportando heridos y viajando en vagones de tren junto a soldados maltrechos. Incluso, enfermó de difteria y disentería (Janz, 1987: 88-89). Pero nunca dejará de imaginar una probable «renovación de la cultura» gracias a la erupción trágica del conflicto bélico. El genio militar irrumpió como una fuerza dionisíaca que hizo temblar los cimientos decadentes de la civilización burguesa; algo muy apasionante asomaba en todo ello.

¿Fue Nietzsche un militarista pangermanista o un vulgar chauvinista? Creemos que no. Sin embargo, tampoco se hallaba totalmente alejado de semejante universo ideológico. En la proyección originaria del libro sobre la tragedia griega, finalmente matizado, la guerra - como elemento constitutivo de la vida - desempeñaba una función más preponderante que en la redacción definitiva. Pero sí plasmó sus ideas con toda nitidez en el prólogo para un libro que nunca fue escrito y que llevaba por título El Estado griego (Nietzsche, 2011: 551-558). Cosima Wagner recibió este texto los primeros días de enero de 1873 , aunque en realidad se trataba de una réplica casi exacta de un fragmento póstumo de comienzos de 1871, es decir, un texto enteramente contemporáneo a la redacción de El origen de la tragedia. De hecho, estaba pensado para aparecer en esta, pero Nietzsche decidió retirarlo de la versión final. ¿Qué le indujo a ello? Quizás fue algún prudente consejo de los Wagner, o tal vez la sencilla consideración de que semejante obra ya era, de por sí, una provocación para la ciencia filológica de la época. El contenido explosivo de $E l$ Estado griego, en ese sentido, habría añadido aún más combustible al previsible escándalo académico. Sea como fuere, su «filosofía social», por así decir, estaba ya contenida en estas primeras piezas o movimientos de su obra y, desde luego, no se desprendía de ella demasiado humanitarismo... En esos pasajes se valoraba aquella crueldad arcaica que, en Homero, ya se encontraba algo atenuada y dulcificada, porque en el mundo prehomérico esa bestialidad amoral y despiadada habíase desplegado todavía con mayor frenesí. La guerra, en definitiva, nos reconectaba con ese mundo casi perdido; la deflagración belicosa permitía que aflorasen, desde el abismo más profundo de la vida, esas energías dionisíacas siempre subyacentes pero secularmente silenciadas y olvidadas (Safranski, 2001: 69-73). Nietzsche detestó el blandengue pacifismo y mitificó en innumerables ocasiones el fuego apabullante del ardor guerrero.

Cuando dio comienzo la guerra franco-alemana, el 19 de julio de 1870, el joven profesor de la Universidad de Basilea no dudó en presentarse como voluntario al servicio del ejército alemán. El 8 de agosto escribía la siguiente petición a una de las autoridades que habían de concederle el permiso pertinente:

En la situación actual de Alemania no puede resultarle inesperada mi decisión de cumplir yo también mis deberes para con la patria. Con esta intención me dirijo a usted para pedir del ilustre Consejo de Educación, a través de su mediación, dispensa de trabajo para la última parte del semestre de verano. Mi decisión está ahora tan robustecida que sin vacilación alguna me puedo hacer útil como soldado o como enfermero. Nadie como una autoridad suiza en materia de educación puede encontrar tan natural y tan justo que yo deba echar el pequeño óbolo de mi aportación personal en las arcas de la patria, 
como ofrenda. Si recapacito en las obligaciones de las que soy responsable en Basilea, me resulta claro que, ante la tremenda llamada de Alemania a que cada uno cumpla con su obligación alemana, solo violentándome penosamente y sin auténtico provecho podría sujetarme a ellas. (Janz, 1987: 86-87)

El 11 de agosto recibió la dispensa solicitada, si bien únicamente como enfermero, en consideración a la neutralidad suiza. Nietzsche, imbuido de ferviente patriotismo, salió el 12 de agosto rumbo al conflicto. Su voluntad de sacrificarse por Alemania era francamente irresistible.

\section{No se puede extirpar lo inextirpable}

Nietzsche empleaba su saber filológico como una plataforma desde la cual juzgar y valorar las tendencias culturales de la era moderna (Sánchez Meca, 2017: 83-99). Sostendrá, desde dicha perspectiva, que una misma enfermedad se viene arrastrando a través de los siglos, insidiosamente, desde los tiempos del infame Sócrates. Late un desasosiego indecible en ese diagnóstico. «Nietzsche no declara su desprecio al mundo moderno: lo grita» (Colli, 2000: 211). Giorgio Colli aseguraba, en ese sentido, que todos los elementos teóricos nietzscheanos germinaban en el interior de una «náusea», pues experimentaba un «horror por el presente». Y las arcadas solían verse reflejadas en su verbo, desde luego. El asunto del dolor, como ha señalado el propio Colli (2000: 139-142), es un hilo conductor determinante en el pensamiento nietzscheano. La vida, con su doliente consistencia interna, no puede ser "corregida»; tampoco debiéramos tratar de evadirnos de ella. Ha de aceptarse su dolor, su ínsita injusticia...

Para comprender que algunos de los más importantes aforismos nietzscheanos apuntaban a un enemigo bien tangible, podemos asomarnos a sus textos y comprobar de manera fehaciente que allí se aludía explícitamente al proyecto socialista, al que tildaba de «ensueño». Esto es muy sintomático, pues nos hace comprender que para Nietzsche resultaba del todo inconcebible proyectar una sociedad en la que no operase, invariablemente, la explotación de unos hombres a manos de otros:

La moda es entregarse a toda clase de ensueños, algunos adornados de colores científicos, que nos pintan el estado futuro de la sociedad, cuando se haya despojado de toda «explotación». Esto suena en mis oídos como si se prometiese inventar una forma de vida que se abstuviese de toda función orgánica. La «explotación» no constituye el hecho de una sociedad corrompida, imperfecta o primitiva; es inherente a la naturaleza misma de la vida, es la función orgánica primordial, una consecuencia de la voluntad de poder propiamente dicha, que es la voluntad misma de la vida. Aun admitiendo que esto sea una teoría nueva, es en realidad el hecho primordial de toda la historia. Tengamos la honradez de reconocerlo. (Nietzsche, 2006: 280-281)

Este parágrafo 259 de Más allá del bien y del mal es nuclear para comprender de forma cabal el pensamiento nietzscheano. Los socialistas, ingenuos 
además de decadentes, pretendían extirpar algo que es de suyo inextirpable: la explotación de unos hombres a manos de otros. La naturaleza es irreductiblemente jerárquica y violenta, y en ella los fuertes (los señores) dominan ineluctablemente a los débiles (los siervos). Pero dos milenios de taimado cristianismo, una insidiosa y triunfante popularización del platonismo, habían volteado ese orden natural de las cosas.

La «moral de esclavos», anclada en la cultura europea desde hacía siglos, había subvertido el orden de la "moral de los señores», que fue derrotada a manos de un sutil y deletéreo enemigo. Supongamos que las víctimas, los oprimidos, los que sufren y los esclavos, dice Nietzsche, se pusieran a moralizar; el resultado sería que todo aquello que resulta poderoso, violento, altivo y avasallador sería valorado como "malo»; mientras que la humildad apocada, la piedad derrotada o la «bondad del corazón» serían valorados como «buenos» (Nietzsche, 2006: 281-286). Pero esta moralidad es flagrantemente antinatural, pues contradice el principio último de la vida:

A riesgo de escandalizar a los oídos castos, doy como un hecho que el egoísmo es parte integrante del alma aristocrática; afirmo la creencia inquebrantable de que seres "como nosotros" tienen una absoluta necesidad de otros seres que les estén sometidos y que se sacrifiquen a ellos. El aristócrata acepta su propio egoísmo como un hecho, sin escrúpulos de conciencia, sin el menor sentimiento de dureza, de violencia, de capricho, sino más bien como una peculiaridad que debe hallarse basada en la ley primordial de las cosas. Si quisiese dar un nombre a este sentimiento, diría que "es la justicia misma». (Nietzsche, 2006: 294-295)

El egoísmo de los poderosos se impone, se debe imponer; querer evitarlo es contradecir de forma venenosa el ímpetu profundo y auténtico de la vida. Lawrence J. Hatab (2008) analizó con mucho tino el malhumorado aristocratismo nietzscheano, centrándose sobre todo en las desgarradoras tesis que atraviesan Zur Genealogie der Moral. Sin embargo, Hatab no quiso extraer todas las consecuencias políticas que de ello se derivaban, y aún pretendía descubrir en la filosofía nietzscheana elementos valiosos para una idea agonística de democracia.

Pero pongamos mucha atención a la expresión empleada por Nietzsche, pues resulta harto significativa: esa jerarquización aristocrática, ese vínculo de dominio, es una «ley primordial de las cosas». En ese sentido, para el tipo humano aristocrático, los otros aparecen siempre instrumentalizados. «El hombre que lleva en sí grandes designios considera a todos los que encuentra en su camino como medios para llegar a su objetivo, como freno y obstáculo o como un alto y un reposo pasajero» (Nietzsche, 2006: 304). Resultaría contrario al ser mismo de la vida, según se desprende de lo antedicho, pretender erigir un orden sociopolítico fundamentado en la cooperación, la fraternidad o la solidaridad. Aunque algunos ácratas nietzscheanos contemporáneos no quieran terminar de comprenderlo, lo cierto es que Nietzsche hubiese esputado sobre el rostro de Kropotkin; hubiese arrojado bilis sobre su «apoyo mutuo». El 
amante de las jerarquías naturales se alejaba un millón de kilómetros de cualquier noción que tuviera algo que ver con la reciprocidad, la confraternización, el comunitarismo o la solidaridad horizontal. Alojado en la mismidad ontológica de todo lo ente - esto es, alojado en la mismidad ontológica de todo lo vivo, de todo lo humano- se halla un principio polémico, competitivo y pujante, cuya última ratio (actuante en todos los confines del mundo) persigue sobreponerse y vencer en esa inapagable contienda vital. Los otros son siempre contrincantes a los que debo derrotar y, en todo caso, mi acercamiento a ellos será siempre instrumental.

Se puede sostener que en Nietzsche no existe una filosofía política explícita y sistemática o, si acaso, que sus ideas políticas habrían quedado expresadas únicamente a modo de «epigramas relámpago y proclamaciones apoteósicas» (Conway, 2011: 15). Pero resulta bastante injustificado, a la luz de lo comentado, construir una imagen de nuestro filósofo en la que este luzca como una suerte de crítico cultural de la decadencia burguesa, tipo Baudelaire (Sauquillo González, 2013); como si en él latiese simplemente una suerte de impulso literario y estético encaminado a transgredir los límites de la propia existencia (Nehamas, 2002). Resulta cuanto menos problemático proyectar la figura de un esteta trasgresor, de un rebelde repleto de pesimismo cultural que percibe y ausculta el espectáculo de la mediocridad imperante en la moderna democracia de masas. Nietzsche, en ese dibujo, sería en todo caso un impugnador del agotamiento espiritual de la humanidad. Desde una doliente soledad, y en un contexto de vulgarización extrema de la vida espiritual, añoraría la trágica presencia de hombres de excepcional talento. Como si todo su lamento fuese por el vaciamiento de la Kultur a manos de la Zivilisation, tal y como este antagonismo se manifestara en Thomas Mann (2011) y en otros muchos. O como si, según indicara Pierre Klossowski (1995: 129), los diversos motivos que en Nietzsche cobraban el aspecto de elementos de filosofía política no fueran, en verdad, sino obsesiones o «reacciones personales con respecto a la cultura en su conjunto" y, de forma preeminente, con respecto a las creaciones artísticas. No podríamos hallar en él pensamientos explícita y consistentemente políticos, vendría a sostenerse. Bajo todas estas perspectivas o lecturas, sería Nietzsche un denunciante de ese inmenso vacío —o desierto- que se iba extendiendo por la superficie y por las entrañas de una cultura europea lastimosamente agostada. Y, si acaso, lo que habría en su pensamiento sería algo así como una rebeldía esteticista que se opondría a la desalmada «frialdad instrumental» de la racionalidad moderna (Cano, 2001). Este nietzscheanismo, así entendido y figurado, estaría latiendo en las ominosas páginas de El trabajador, una obra de 1932 en la que Ernst Jünger (1990) dejaría traslucir un evidente desasosiego por el avance irrestricto de la tecnificación del mundo. Pero es del todo infundada, insistimos, esa figuración de un Nietzsche desentendido de los temblores económico-políticos de su época. De hecho, la coyuntura misma de su tiempo, tan vibrante y convulsiva, determinó profundamente sus concepciones morales y sus interpretaciones de la condición humana. Y le preocupaba sobremanera, digámoslo una vez más, que republi- 
canos radicales, jacobinos o socialistas estuviesen promoviendo un exaltado empoderamiento de la canaille.

Cuando subraya de forma descarnada la desigualdad entre los hombres, y cuando impugna con supremo desdén todos los igualitarismos rousseaunianos y revolucionarios, Nietzsche alberga en su cabeza un modelo de sociedad. No resulta creíble sostener que tales cuestiones le traen sin cuidado. Por ejemplo, en los esbozos de un plan para un libro que nunca llegó a escribir proyectaba dedicar todo un capítulo a teoría del Estado; era el año 1869 (González Varela, 2010: 112). La forma estatal preferente debiera ser aquella capaz de reflejar una auténtica plasmación de los instintos, aquella capaz de permitir una jerarquización aristocrática del orden social, aquella capaz de conservar una plasmación «natural» de las diferencias irreductibles de señores y siervos. En múltiples pasajes, con descarnada y explícita vehemencia, arrojaba vituperios contra los Derechos Fundamentales del Hombre y contra la Dignidad del Trabajo, consignas altamente deletéreas. Sostenía la imperiosa necesidad de que una masa embrutecida siguiera trabajando para una minoría privilegiada, como veremos a continuación. Funesto fue el momento, pensaba, en el que los esclavos fueron estimulados para elevarse más allá de su condición. Pero cuidado, porque no se trataba de una simple «aristocracia intelectual». Nietzsche señalará abiertamente que los verdaderos "genios» solo pueden emerger dentro de una selecta minoría que domine autoritariamente el orden social. De eso se está hablando, del orden social. La "gran cultura» debe ser accesible solo a unos pocos, por lo cual es absurdo postular programas educativos para el pueblo trabajador. Pretender ofrecer una suerte de "formación cultural» generalizada constituía, además, un proyecto verdaderamente antigermano (González Varela, 2010: 115-123 y 147-148). Véanse, en ese sentido, las conferencias que Nietzsche impartió en Suiza en los primeros meses de 1872, en las cuales llegó a señalar a modo de advertencia que una formación educativa generalizada sería la «antesala del comunismo» (Janz, 1987: 142-145).

En muchos de sus fragmentos póstumos Nietzsche aparece extremada y crudamente diáfano en sus planteamientos, y puede sostener sin ambages que las condiciones óptimas para la emergencia de un gran florecimiento artístico, llevado a término por una selecta y genial minoría, solo podrán darse si una inmensa mayoría es sometida mediante un trabajo esclavo. Para que el «tipo superior de hombre» pueda medrar, se precisa de un máximum de explotación de los hombres bajos e inferiores. Y mucha precaución, porque estas proposiciones no son meramente descriptivas, esto es, un modo de comprender lo que fue el pasado de la humanidad; muy al contrario, son aseveraciones normativas acerca de las condiciones que toda sociedad debe cumplir para que dentro de ella pueda germinar una gran cultura. En 1871 lo dejaba escrito:

Para que exista el fundamento de un gran desarrollo artístico, la inmensa mayoría tiene que ser sometida, mediante la esclavitud, al servicio de una minoría [...]. A sus expensas, por medio de un trabajo excedente, aquella clase privilegiada es apartada de la lucha por la existencia, para crear entonces un 
nuevo mundo de necesidades. Según esto, hemos de comprender adecuadamente, cuando caracterizamos las horrorosas condiciones fundamentales de toda formación, que la esclavitud pertenece a la esencia de una cultura [...] La pobreza de la masa que vive penosamente se ha de aumentar todavía para hacer posible a un número de hombres olímpicos la producción del mundo del arte. Aquí se encuentra la fuente de aquella rabia mal disimulada que los comunistas y los socialistas, y también sus descendientes más pálidos, la raza blanca de los liberales de todas las épocas, han alimentado contra el arte, pero también contra la antigüedad clásica. (Nietzsche, 2004: 85)

Una masa humana sobreexplotada es imprescindible para el surgimiento esplendoroso de la alta cultura, apuntaba Nietzsche. Y apostillaba, sin escrúpulo aparente, que la masa de los que «viven penosamente» debe aumentar.

Vanessa Lemm (2013) ha sostenido que no debe otorgarse al aristocratismo nietzscheano un estatuto explícitamente político, pues evocaría más bien una cuestión espiritual. No compartimos esta tesis. Su aristocratismo cultural, en realidad, deja traslucir la nostalgia por una época en la que los valores culturales constituían un privilegio de clase, un excelso reino del que estaban excluidas (y deberían seguir estándolo por siempre) las masas plebeyas. Los antiguos griegos eran lo suficientemente honrados como para reconocer abiertamente la necesidad de la esclavitud, el único humus a partir del cual podían crecer las bellas flores de la auténtica cultura. Y proclamar, como hacen los revolucionarios modernos, una democratización social destinada a obtener el bienestar del mayor número posible de personas, pensaba, nos ha de conducir a un infecto lodazal de mediocridad en el que jamás volverán a surgir genios o grandes personalidades. Nietzsche está diciendo algo tan grave como lo siguiente: la justicia distributiva y la cultura genuina son incompatibles. ¿Cómo ignorar, en nuestra lectura de Nietzsche, un dictamen tan demoledor?

Manifestando un odio muy evidente a todo aquello que oliese lo más mínimo a igualitarismo político, Nietzsche entiende que la moderna democracia no es más que la irrefrenable decadencia del Estado. El llamado conflicto social, además, existe porque los patrones modernos no saben mandar; incapaces de legitimar moralmente su jerarquía, no pueden infundir respeto en el obrero. El virus infeccioso del socialismo palpita en el corazón de las masas porque la casta dirigente actual ya no alberga el pathos de los auténticos hombres superiores. Solo estos podrían impedir el desgarrador conflicto, enseñando a los obreros a sentir y vivir como soldados, con lo cual ya no cuestionarían el orden jerárquico ni experimentarían su sometimiento como penoso (Jaspers, 1963: 394). Resultaría difícil, en consecuencia, hallar connotaciones libertarias o emancipadoras en esta filosofía. Porque si para socialistas y anarquistas la explotación se halla fundada en determinadas condiciones históricas de tipo socioeconómico, que son contingentes y por ende susceptibles de ser transformadas, superadas o al menos corregidas en sus efectos más perniciosos, para Nietzsche la «explotación» de unos a manos de otros no es fruto de una sociedad desequilibrada, injusta o corrompida. No, esa explotación es un dato inamovible, un factor natural en el orden eterno del mundo; algo que perte- 
nece a la esencia misma de la vida. Pero los socialistas (los anarquistas, hemos de recordarlo, también venían incluidos en esta categoría), herederos seculares del socratismo y del cristianismo, han sucumbido a esa necia quimera. Nietzsche localizaría en todos ellos la mezcolanza más acabada de todo lo despreciable; un suntuoso compendio de todo lo mórbido. Oigámosle: «Los insatisfechos han de tener algo de lo que dependa su corazón: por ejemplo, Dios. Ahora, donde falta este, muchos de los que en otros tiempos se habían agarrado a Dios aceptan por ejemplo el socialismo» (Nietzsche, 2004: 159). Y con toda su mordacidad, sentenciaba en otro pasaje:

El Evangelio: la noticia de que se ha abierto un acceso a la felicidad para los inferiores y los pobres, de que uno no tiene que hacer nada más que liberarse de la institución, de la tradición, de la tutela de los estamentos superiores; hasta aquí, el avance del cristianismo no es otra cosa que la típica doctrina socialista [...] En general, todo esto es un síntoma de que los estratos sociales inferiores han recibido un trato humanitario, de que ya saborean con la lengua una dicha prohibida para ellos... (Nietzsche, 2004: 190)

Resulta inverosímil, a la luz de semejantes pasajes, sostener que Nietzsche no albergaba una visión política muy determinada.

\section{A modo de conclusión}

Afirmaba Julio Quesada (1988: 360), ahondando precisamente en una línea «exculpatoria» que nosotros queremos criticar de manera frontal, que en Nietzsche no había biologismo de ningún tipo, y también que su calificación como «reaccionario» es fruto de una mala interpretación. En el subtítulo del ensayo de Quesada se menciona el término política, pero cualquier referencia a la dimensión política nietzscheana se realiza siempre bajo un prisma estetizante. Se pone en juego, así, una hermenéutica de la exoneración. «Si ahí se habla de "señores" y de "esclavos", lejos estaba Nietzsche de pensar en los "junker" y "obreros" alemanes, como creyó Lukács. Porque lo que separa verdaderamente una moral de otra no es sino el "si" o el "no" dado a la vida" (Quesada, 1988: 361). ¿De verdad se encontraba Nietzsche tan lejos de pensar en las clases trabajadoras y en los Junker prusianos, cuando trazaba sus incendiarias reflexiones? La maniobra, lo comprobamos una vez más, consiste en desactivar la carga explícitamente sociopolítica de sus pensamientos. Para ello, se minusvaloran o se alegorizan los materiales textuales "desagradables», o sencillamente se silencian. Y lo que aparece como verdaderamente injustificable es la construcción de un Nietzsche «antipolítico», tal y como hizo Walter Kaufmann (1974), quien llevó a cabo una portentosa labor de edición y traducción al inglés de buena parte de la obra nietzscheana, es cierto, siendo así que sus interpretaciones sobre la misma han ejercido mucha influencia en el mundo anglosajón. Sin embargo, en su afán por expurgar al filósofo alemán de cualquier mínimo rastro de chovinismo germanófilo, antisemitismo, judeofobia, elitismo antidemocrático, racismo eugenésico o aristocratismo socioeconómico, en ese afán, decíamos, terminó por destilar un 
Nietzsche cercenado y adulterado. Empeñándose en sostener que los filosofemas nietzscheanos se hallan completamente alejados de la política y de lo político, Kaufmann contribuyó de forma notable a la consolidación de esa imagen de Nietzsche que nosotros venimos criticando de manera frontal.

Debemos concluir que un pensador de su talla no pudo permanecer al margen de la gran batalla, social y política, que atravesó su incandescente siglo. Resulta crucial, por ende, poner la filosofía nietzscheana en directo diálogo con las tradiciones ideológicas y políticas de su tiempo (Ottmann, 1987). Porque la de Nietzsche es, también, una filosofía política. De hecho, compartiremos las tesis de Domenico Losurdo (2004), que en su imprescindible Nietzsche, il ribelle aristocrático argumentaba de forma muy consistente que la obra nietzscheana solo podía comprenderse como la filosofía de un intelectual orgánico de la contrarrevolución; y entenderemos, por ello, como fundamentalmente errónea toda lectura que haya pretendido despolitizarla o, en todo caso, que haya querido politizarla en un sentido izquierdista (incluyendo aquí a la tradición ácrata), progresista o emancipador.

El «renacimiento» de la filosofía nietzscheana acaecido en la década de 1960, al calor de la publicación de los cursos de Martin Heidegger, ofreció la imagen de un pensamiento «inactual», esto es, una filosofía enmarcada en parámetros de apoliticidad. Solo de tal manera pudo ser recodificada, una década después, como una filosofía apta para proyectos teóricos más o menos contraculturales e incluso más o menos izquierdistas (en su rama más «anarcodeseante», podríamos decir). Curiosa paradoja, por lo tanto: un resurgir despolitizador de Nietzsche, en primer lugar, y una posterior "politización» estético-anarquizante. A partir de entonces, desde los años setenta hasta hoy, se aquilató un consenso casi inexpugnable, un verdadero canon interpretativo que prohibía terminantemente comprender su pensamiento como eminentemente político y, además, como radicalmente reaccionario o contrarrevolucionario. Compartimos, por ello, la sorpresa de Norberto Bobbio (1989: 286), que ya a finales de los años ochenta se maravillaba de que el mismo filósofo de las aristocracias guerreras y de los himnos a la despiadada voluntad de poder se hubiera erigido, por alguna suerte de sortilegio extravagante, en el icono de las izquierdas contraculturales. Semejante operación fue llevada a cabo, primordialmente, por la academia francesa (Le Rider, 2002).

$\mathrm{Al}$ igual que Losurdo, queremos comprender a Nietzsche en las coordenadas de su propio tiempo, sin convertirlo en un nazi avant la lettre. El pensador italiano señalaba, con ironía, que el filósofo fue contemporáneo del segundo Reich, no del tercero, y un Reich de diferencia no es poca cosa. De lo que se trata, en cambio, es de comprender que toda su obra se sitúa en el eje revolución-contrarrevolución, posicionándose abiertamente en las trincheras intelectuales de la segunda. La abominación de las ideas revolucionarias y de su concomitante "plebeyización de la cultura» constituyó un motivo constante y determinante a lo largo de toda su obra. Su pensamiento, en diálogo directo con las grandes corrientes político-ideológicas de su tiempo, se construyó en esa tensión. Es imposible comprender a Nietzsche sin entender que todas sus 
energías intelectivas, pasionales y vitales estuvieron volcadas en una permanente réplica a las ideas políticas revolucionarias. Republicanos, jacobinos, sufragistas, comuneros, igualitaristas, demócratas, socialistas, anarquistas, reformistas sociales de toda condición... Contra todos ellos piensa y escribe. Y su lenguaje, desalmado y virulento en demasiadas ocasiones, no es metafórico. Deben respetarse los contextos de significación de los términos por él empleados, ubicar su lenguaje y el contenido de sus ideas en los debates de su época, porque cuando Nietzsche habla de la necesidad de erigir un orden social donde existan el trabajo servil y el esclavo, no deben buscarse alegorías exculpatorias. Lo dice en un sentido absolutamente literal y normativo.

Para terminar, querríamos mencionar un libro del filósofo francés Michel Onfray, que lleva por título La inocencia del devenir. La vida de Friedrich Nietzsche (2009). En él se ensaya un guion cinematográfico sobre la vida del filósofo alemán, y el resultado es bastante brillante. Pero es de destacar que todos los episodios biográfico-intelectuales que hemos referido en este capítulo no aparecen. Brillan por su ausencia. No vemos una sola escena en la que aparezca refiriéndose, por ejemplo, a la Comuna de París, o profiriendo agrios insultos contra los socialistas y los anarquistas. Tampoco vemos a nuestro personaje quejarse amargamente de los dislates democráticos; del sufragio universal, por ejemplo. Y lo curioso es que Onfray, en la introducción que precede al guion — que lleva por título "Contar en imágenes una vida filosófica»— había arremetido, precisamente, contra todos esos cineastas incapaces de respetar los rasgos primordiales o las peripecias cruciales del personaje cuando de una película histórica o biográfica se trataba. Onfray había sucumbido, quizás sin saberlo, a la lectura despolitizadora de Nietzsche y, por ende, había recaído en la misma negligencia que él mismo acababa de denunciar.

Resulta muy ilustrativo observar, por poner un ejemplo del ámbito académico español, cómo Miguel Morey «ignora» en todo momento la dimensión política de Nietzsche. En Vidas de Nietzsche (2018), una magnífica biografía intelectual, no hallaremos una sola referencia a sus textos más específicamente políticos. En sus cuatrocientas cincuenta páginas apenas encontraremos la voz "política». Leyendo esta obra, documentadísima y repleta de episodios de la vida de Nietzsche, pareciera que este jamás prestó atención a las cuestiones sociales; pareciera que jamás mostró ni el más mínimo interés por el mundo político. Y eso es falso de toda falsedad. Debemos concluir, en cualquier caso, que no es un descuido de Morey; bien al contrario, opera un ocultamiento sistemático del «Nietzsche político», un silenciamiento deliberado.

El crítico y filósofo danés Georg Brandes, que mantuvo correspondencia personal con Nietzsche desde finales de 1887 y a lo largo de 1888 (esto es, casi hasta el mismo momento de su brote de salvaje megalomanía y del subsecuente colapso nervioso), sostenía que su filosofía debería ser definida como una suerte de "radicalismo aristocrático». Y así se lo hizo saber en una carta. Nietzsche, en otra misiva escrita desde Niza en diciembre de 1887, le responde amistosamente: «La expresión "radicalismo aristocrático", que usted me dirige, me agrada. Permítame decirle que es lo más fuerte que de mí se ha dicho» 
(Brandes, 2008: 78). La predominancia meramente cuantitativa de la masa plebeya le resultaba, a Nietzsche, completamente insoportable. ¿No debiera reservarse la gran felicidad solo a los mejores, a los genios sobresalientes capaces de alzarse e imponerse en la gloria de su propia fuerza? Brandes, que simpatizaba con las ideas nietzscheanas (divulgó sus ideas en Dinamarca y en toda Escandinavia), compartía plenamente aquella tesis según la cual la moral propia de los esclavos germinaba a partir del puro resentimiento: la impotencia se había convertido en bondad; la debilidad se había transformado en virtud. A «no poder vengarse» lo denominaron «no querer vengarse». Nunca hubo jugada más capciosa: inventaron la "Justicia», sacra palabra escrita con mayúscula; Justicia en sí. Esta habría sido la monumental y astuta operación de los débiles, según Nietzsche. Con semejante maniobra se había consumado una secular derrota del espíritu aristocrático.

Creemos que Brandes comprendió bien lo que se estaba jugando con semejantes propuestas; lo comprendió mucho mejor, de hecho, que ulteriores hermeneutas del siglo xx. Y nos parece digna de mención esa alusión al derecho, pues este quedaría comprendido como otra de las cristalizaciones de esa «astucia» manejada por los débiles. El derecho de un orden político democrático, en la visión nietzscheana, no sería más que una vil artimaña de supervivencia tejida por las castas inferiores. El derecho, en suma, sería una mediación opuesta a la esencia de la vida, que no es sino eterna lucha. Una vida que en Nietzsche ya no equivalía meramente a "voluntad de vivir» (Wille sum Leben), a "lucha por la existencia» (Struggle for life) o a un conatus que desea "permanecer en el ser» casi por mera inercia. No. La vida es mucho más que todo eso. Porque en el pensamiento del Dioniso alemán no se trata únicamente de sobrevivir a cualquier precio, de forma adaptativa. «Según él, la lucha se establece, no por la vida, la vida desnuda, sino por el poder» (Brandes, 2008: 78). La vida es, en su consistencia última, una pujanza irreprimible hacia el acrecentamiento del propio poder. Vivir es esencialmente despojar, combatir, aplastar, herir, imponerse y violentar (Nietzsche, 2006: 280). Lo absolutamente determinante, aquello en torno a lo cual bascula todo lo demás, es precisamente el Macht.

Las ilusiones progresistas quedan completamente aniquiladas en la filosofía nietzscheana, calcinadas de raíz. Su amigo epistolar lo expresó de nuevo con plástica nitidez, sin ornamentos:

El gozo que inspira a Nietzsche la lucha en tanto que lucha, completamente opuesto a la manera de ver inspirada por el humanitarismo moderno, es muy característico. Para él, la magnitud de un progreso se mide por la importancia de los sacrificios que exige. Una higiene que mantiene vivos a millones de seres débiles e inútiles, que hubieran debido morir, no es un progreso verdadero. Un tranquilo bienestar medio asegurado a un número lo mayor posible de criaturas miserables, que en nuestros días se llaman seres humanos, no representa tampoco un progreso grande y verdadero. (Brandes, 2008: 49)

Las utopías del porvenir con las que Nietzsche soñaba tenían que ver con la "cría» de un género de hombres superiores, dominantes y grandiosos, pero 
jamás con el progreso de las «mayorías sociales». Deseaba hombres capaces de movilizar instintos salvajes, sin la mediación abúlica del "remordimiento» y sin la introyección putrefacta del "sentimiento de culpa» (ese mal que se infligen a sí mismos los que odian la vida, los que no soportan su belleza doliente, los que no son capaces de asumir su tensión violenta e inmisericorde). Hombres, así lo anhelaba, que supieran restaurar la bondad del «afán de dominio», ese mismo que fue valorado o estigmatizado como «malvado» por parte de una moral demasiado aberrante que se tornó hegemónica en la cultura occidental. Incluso Georges Bataille (1979: 205-209), gran admirador de Nietzsche, apuntaba no obstante que en la obra de su querido filósofo latían ciertas exaltaciones de la crueldad y del salvajismo.

\section{Referencias bibliográficas}

Ansell-Pearson, Keith (1994). An introduction to Nietzsche as political thinker. Cambridge: Cambridge University Press.

Bataille, Georges (1979). Sobre Nietzsche: Voluntad de suerte. Madrid: Taurus.

Bоввіо, Norberto (1989). Perfil ideológico del siglo xx en Italia. México: Fondo de Cultura Económica.

BRANDEs, Georges (2008). Un ensayo sobre el radicalismo aristocrático. México: Sexto Piso.

Brobjer, Thomas H. (2008). Nietzsche's Philosophical Context: An Intellectual Biography. Champaign: University of Illinois Press.

Cano, Germán (2001). Nietzsche y la crítica de la modernidad. Madrid: Biblioteca Nueva.

Colli, Giorgio (2000). Introducción a Nietzsche. Valencia: Pre-Textos.

Conway, Daniel W. (2011). Nietzsche y lo politico. Buenos Aires: Prometeo Libros.

Cristi, Renato y Velásquez, Óscar (2018). Nietzsche y el aristocratismo de Teognis. Santiago de Chile: LOM.

Deleuze, Gilles (2000). Nietzsche. Madrid: Arena.

Esteban Enguita, José Emilio (2004). El joven Nietzsche: Politica y tragedia. Madrid: Biblioteca Nueva.

Fink, Eugen (1976). La filosofía de Nietzsche. Madrid: Alianza.

GonzÁlez VARELA, Nicolás (2010). Nietzsche contra la democracia. Barcelona: Montesinos.

Habermas, Jürgen (1982). Sobre Nietzsche y otros ensayos. Madrid: Tecnos.

Hatab, Lawrence J. (2008). Nietzsche's On the Genealogy of Morality: An Introduction. Cambridge: Cambridge University Press.

Heidegger, Martin (2013). Nietzsche. Barcelona: Ariel.

Janz, Curt Paul (1987). Friedrich Nietzsche: Los diez años de Basilea (18691879). Vol. 2. Madrid: Alianza.

JASPERS, Karl (1963). Nietzsche. Buenos Aires: Editorial Sudamericana. Jünger, Ernst (1990). El trabajador: Dominio y figura. Barcelona: Tusquets.

Kaufmann, Walter (1974). Nietzsche: Philosopher, psychologist, antichrist. Londres: Princeton University Press. 
KLossowski, Pierre (1995). Nietzsche y el circulo vicioso. Buenos Aires: Altamira.

Lemm, Vanessa (2013). Nietzsche y el pensamiento politico contemporáneo. Santiago de Chile: Fondo de Cultura Económica.

Le Rider, Jacques (2002). «Nietzsche, una pasión francesa: Cien años de recepción de Nietzsche en Francia». Enrahonar, 35, 89-100. <https://doi.org/10.5565/rev/enrahonar.381>

Losurdo, Domenico (2004). Nietzsche, il ribelle aristocrático: Biografia intellettuale e bilancio critico. Turín: Bollati Boringhieri.

Löwith, Karl (1968). De Hegel a Nietzsche: La quiebra revolucionaria del pensamiento en el siglo XIX. Buenos Aires: Editorial Sudamericana.

LukÁcs, Georg (1968). El asalto a la razón: La trayectoria del irracionalismo desde Schelling hasta Hitler. Barcelona: Grijalbo.

Mann, Thomas (2011). Consideraciones de un apolitico. Madrid: Capitán Swing. Montinari, Mazzino (2003). Lo que dijo Nietzsche. Barcelona: Salamandra.

Morey, Miguel (2018). Vidas de Nietzsche. Madrid: Alianza.

Nehamas, Alexander (2002). Nietzsche: La vida como literatura. México: Fondo de Cultura Económica. Madrid: Turner.

Nietzsche, Friedrich (1988). El caminante y su sombra. Madrid: Marte.

- (1998). Asi habló Zaratustra. Madrid: Alianza.

- (2001). Humano, demasiado humano. Madrid: Edaf.

- (2004). Fragmentos póstumos sobre politica. Madrid: Trotta.

- (2006). Más allá del bien y del mal: Preludio para una filosofía del futuro. Madrid: Edaf.

- (2009). Sobre el porvenir de nuestras escuelas. Barcelona: Tusquets.

- (2011). «El Estado griego». En: Obras completas. Volumen 1. Escritos de juventud. Madrid: Tecnos, 551-558.

OnfraY, Michel (2009). La inocencia del devenir: La vida de Friedrich Nietzsche. Barcelona: Gedisa.

Ottmann, Henning (1987). Philosophie und Politik bei Nietzsche. Berlín: Walter de Gruyter.

Polo Blanco, Jorge (2020). Anti-Nietzsche: La crueldad de lo politico. Madrid: Taugenit.

Quesada, Julio (1988). Un pensamiento intempestivo: Ontología, estética y politica en F. Nietzsche. Barcelona: Anthropos.

SAFranSKI, Rüdiger (2001). Nietzsche: Biografia de su pensamiento. Barcelona: Círculo de Lectores.

Salem Himmich, Ben (2002). "Cien años después: Nietzsche con rostro humano». Enrahonar, 35, 45-54. $<$ https://doi.org/10.5565/rev/enrahonar.377>

Sánchez Meca, Diego (2017). El itinerario intelectual de Nietzsche. Madrid: Tecnos.

SAUQuillo González, Julián (2013). «Fascinación y terror ante la modernidad: Nietzsche, lector de Baudelaire». En: Sanz Burgos, Raúl (coord.). Nietzsche: Modernidad y politica. Madrid: Dykinson, 17-76. 
Siemens, Herman W. y Roodt, Vasti (eds.) (2008). Nietzsche, Power and Politics: Rethinking Nietzsche's Legacy for Political Thought. Berlín: De Gruyter.

Vatтimo, Gianni (2001). Introducción a Nietzsche. Barcelona: Península.

Jorge Polo Blanco es doctor en Filosofía por la Universidad Complutense de Madrid. Ha publicado tres libros: Anti-Nietzsche. La crueldad de lo politico (Taugenit Editorial, 2020), La economía tiránica. Sociedad mercantilizada, dictadura financiera y soberanía popular (Carpe Noctem, 2015) y Perfiles posmodernos. Algunas derivas del pensamiento contemporáneo (Editorial Dykinson, 2010).

Jorge Polo Blanco has a PhD in Philosophy from the Complutense University of Madrid. He has published three books: Anti-Nietzsche. La crueldad de lo politico (Taugenit Editorial, 2020), La economia tiránica. Sociedad mercantilizada, dictadura financiera y soberania popular (Carpe Noctem, 2015) and Perfiles posmodernos. Algunas derivas del pensamiento contemporáneo (Editorial Dykinson, 2010). 